\title{
Regeneración de yemas adventicias en segmentos de hojas y entrenudos de Balfourodendron riedelianum (Engl.) Engl.
}

\section{Regeneration of adventitious buds on leaf and internode segments of Balfourodendron riedelianum (Engl.) Engl.}

\author{
Evelyn Raquel Duarte ${ }^{1}$
}

Duarte, E. R. (2022). Regeneración de yemas adventicias en segmentos de hojas y entrenudos de Balfourodendron riedelianum (Engl.) Engl. Colombia Forestal, 22(1), 67-76.

Recepción: 14 de marzo 2021

\section{Resumen}

La finalidad de este estudio fue evaluar la capacidad de regeneración de yemas adventicias en explantes de segmentos de hojas y entrenudos provenientes de plantas in vitro. Para ello, fueron germinadas semillas de Balfourodendron riedelianum en condiciones in vitro, y luego de un mes los explantes de hojas y entrenudos fueron cultivados en un medio Murashige y Skoog suplementado con combinaciones ANA (0.01 mg. $\left.\mathrm{L}^{-1}\right)$, BAP $\left(0.1 \mathrm{mg} \cdot \mathrm{L}^{-1}\right)$ y TDZ $(0.1$,

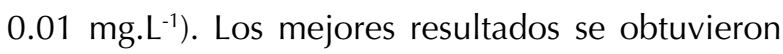
cuando los fragmentos de entrenudos fueron cultivados en $0.1 \mathrm{mg} . \mathrm{L}^{-1}$ de BAP y $0.01 \mathrm{mg} . \mathrm{L}^{-1}$ de TDZ, donde el $26.67 \pm 5.77 \%$ de los explantes brindaron $12 \pm 4.36 \%$ de yemas por explantes. Se concluyó que los explantes de segmentos de hojas y entrenudos de $B$. riedelianum son aptos para inducir yemas adventicias.

Palabras clave: fitohormonas, in vitro, organogénesis, yemas adventicias.
Aprobación: 11 de agosto 2021

\begin{abstract}
The purpose of this study was to evaluate the regeneration capacity of adventitious buds in explants of leaf segments and internodes from in vitro plants. For this purpose, seeds of Balfourodendron riedelianum were germinated under in vitro conditions, and after one month, leaf and internode explants were grown on Murashige and Skoog medium supplemented with combinations of ANA (0.01 mg. $\left.\mathrm{L}^{-1}\right)$, BAP $\left(0.1 \mathrm{mg} . \mathrm{L}^{-1}\right)$ and TDZ $(0.1,0.01$ $\left.\mathrm{mg} \cdot \mathrm{L}^{-1}\right)$. The best results were obtained when internode fragments were grown in $0.1 \mathrm{mg} . \mathrm{L}^{-1}$ of BAP and $0.01 \mathrm{mg} \cdot \mathrm{L}^{-1}$ of TDZ, in which $26.67 \pm 5.77 \%$ of explants provided $12 \pm 4.36 \%$ of buds per explant. It was concluded that explants of leaf segments and internodes of $B$. riedelianum are suitable to induce adventitious buds.
\end{abstract}

Keywords: phytohormones, in vitro, organogenesis, adventitious buds.

1 Facultad de Ciencias Forestales, Universidad Nacional de Misiones (UNaM), Bertoni 124 Km 3, Eldorado, Misiones, Argentina. evelynduarte1982@gmail.com 


\section{INTRODUCCIÓN}

Balfourodendron riedelianum (Engl.) Engl. es una especie arbórea de la familia Rutaceae que crece naturalmente en el Bosque Atlántico entre Brasil y Argentina. Es una especie de alto valor ecológico y económico por poseer una madera usada en muebles de lujo, construcciones civiles, decoraciones, artesanías y carpintería en general (Assad et al., 2020; Benítez et al., 2018; Lisboa et al., 2016; Schneider et al., 2017). Sin embargo, la sobreexplotación para la utilización de su madera y la deforestación causada por el uso de tierras destinadas a labores agrícolas generó una pérdida del recurso a tal punto que se encuentra actualmente en peligro (Aguiar et al., 2020). Siendo originaria de uno de los hotspots más amenazados del mundo, esta especie y todo su hábitat podrían desaparecer si no se adoptan medidas inmediatas que protegan las especies de este hotspot y los remanentes de su hábitat (Aguiar et al., 2020; FVSA y WWF, 2017; Lanzone et al., 2018). Por esta razón, es necesario generar de manera urgente estrategias que permitan la conservación de esta especie a largo plazo. De ahí la importancia de elaborar protocolos de propagación para obtener plantas que se adapten a las condiciones de campo y admitan su supervivencia a través del tiempo (Álvarez et al., 2011). En este sentido, una herramienta biotecnológica útil y de amplio uso en los últimos años para el rescate, la conservación y la multiplicación de especies arbóreas nativas es el cultivo in vitro (Vidal Cob-Uicab et al., 2011). Las técnicas de este cultivo ofrecen la ventaja que de una pequeña porción de la planta -conocido con el nombre de explante- se pueden propagar masivamente aquellos ejemplares que poseen las mejores características morfológicas y adaptativas. Además, a través del cultivo in vitro se pueden establecer protocolos de propagación eficientes y económicos que pueden ser utilizados con éxito en programas de reforestación (Álvarez et al., 2011).

Entre las técnicas del cultivo in vitro se encuentra la regeneración vía organogénesis, que es la producción de vástagos unipolares con la capacidad de enraizar espontáneamente o con reguladores de crecimiento. Ocurre por estimulación de las yemas preexistentes (axilares) o a partir del tejido de novo (yemas adventicias). La multiplicación de yemas preformadas se da generalmente sin formación de callo y tiene la desventaja de limitar la producción de brotes, aunque puede aumentarse la tasa de multiplicación por medio de subcultivos posteriores. En el caso del desarrollo de yemas adventicias se requiere inducir formación de tejido meristemático con o sin formación de callo (organogénesis directa e indirecta), utilizando reguladores de crecimiento para estimular, en primer lugar, la diferenciación del primordio y luego el crecimiento del vástago. Así, con esta técnica se obtiene una mayor cantidad de brotes por unidad de superficie, pues no es necesario la presencia de meristemas en el tejido que se utiliza como explante (Olmos et al., 2010).

Si bien la organogénesis adventicia fue obtenida exitosamente en numerosas especies leñosas como Phellodendron amurense, Aegle marmelos y Murraya koenigii (Khatik y Joshi, 2017; Kumari et al., 2015; Wang et al., 2011), muchas especies arbóreas pueden ser recalcitrantes, pues no es posible su regeneración in vitro. La utilización de explantes se limita, entonces, a embriones zigóticos o partes de plántulas, y estos, a su vez, pueden presentar dificultades -en el cultivo in vitro- por la lixiviación de fenoles (Bonga et al., 2010; Villalobos y Thorpe, 1991).

Además de los inconvenientes que presentan algunas especies leñosas, la morfogénesis in vitro está altamente influenciada por factores como la variación genética, la condición fisiológica de la planta, las condiciones de cultivo (Córdova et al., 2014; Domínguez-Perales et al., 2016; Villanueva et al., 2013) y el tipo de explante, hormona y dosis utilizada (Rodríguez-Beraud et al., 2014). Por lo tanto, es de vital importancia realizar estudios para identificar los factores que influyen en el cultivo in vitro de cada especie, a fin de generar protocolos confiables y reproducibles. Con esta iniciativa en 
mente, el primer y único estudio publicado con la intención de realizar protocolos in vitro de la especie fue el de Niella et al. (1996), pero sin resultados positivos en la organogénesis de explantes de hojas.

Por lo antes expuesto, en el presente estudio se investigó la factibilidad de inducir yemas adventicias en segmentos de hojas y entrenudos para iniciar protocolos de propagación que permitan multiplicar vegetativamente esta especie en un corto periodo de tiempo y en espacios reducidos.

\section{MATERIALES Y MÉTODOS}

\section{Origen de las semillas}

Los frutos de los cuales se extrajeron las semiIlas para el experimento fueron cosechados en la Reserva de Uso Múltiple (26 $54^{\prime} 59^{\prime \prime}$ latitud sur $54^{\circ} 12^{\prime} 18^{\prime \prime}$ longitud oeste) de la Facultad de Ciencias Forestales de la Universidad Nacional de Misiones (UNaM), localizada en el Departamento de Guaraní (Argentina), y luego almacenadas en bolsas de polietileno dentro de refrigeradores a $4{ }^{\circ} \mathrm{C}$ hasta realizar el ensayo, que se llevó a cabo en el Laboratorio de Propagación Vegetativa de la Facultad de Ciencias Forestales de la UNaM.

\section{Desinfección y germinación de semillas}

En primer lugar, se procedió a quitar las semillas de los frutos con un bisturí; luego, en condiciones de asepsia y en cámara de flujo laminar, las semiIlas fueron sometidas a una desinfección superficial, que consistió en sumergirlas inicialmente en una solución de peróxido de hidrógeno $\left(\mathrm{H}_{2} \mathrm{O}_{2}\right)$ de 30 volúmenes durante 16 horas, después en una solución de alcohol del 70 \% por un minuto y, para terminar, en una solución $\mathrm{NaClO}$ al $1.5 \%$ con 3 gotas de detergente neutro por 20 minutos; para finalizar, la desinfección se realizó con tres enjuagues de agua destilada estéril.
El medio utilizado para la germinación consistió en el uso de sales básicas del medio MS en su concentración original (Murashige y Skoog, 1962), adicionado con 30 g.L. ${ }^{-1}$ de sacarosa, 6 g. $\mathrm{L}^{-1}$ de agar-agar, libre de reguladores del crecimiento y ajustado a un $\mathrm{pH}$ de 5.8 con $\mathrm{KOH}$ o $\mathrm{HCl}$ previo adición del agente gelificante; posteriormente, fue esterilizado en una autoclave por calor húmedo a una presión de 1.46 k.cm-2 durante 20 minutos. Las semillas fueron cultivadas individualmente en condiciones de asepsia en tubos de $15 \mathrm{~mL}$ de capacidad que contenían $4 \mathrm{~mL}$ de medio cultivo $y$, a continuación, incubados por un periodo de 30 días en condiciones ambientales de luz $\left(116 \mu \mathrm{mol} . \mathrm{m}^{-2} . \mathrm{s}^{-1}, \mathrm{PAR}\right.$, fotoperíodo de 16 horas), a temperatura controlada $\left(27 \pm 2{ }^{\circ} \mathrm{C}\right)$.

\section{Inducción de yemas adventicias en medio semisólido}

Para la inducción de la organogénesis se utilizaron como explante segmentos de entrenudos (5 mm) y hojas $(5 \times 5 \mathrm{~mm})$ obtenidos de plantas germinadas in vitro de 1 mes de edad. Estos segmentos fueron cultivados individualmente en condiciones de asepsia en tubos de $10 \mathrm{~mL}$ de volumen, a los cuales se les dispensó $4 \mathrm{~mL}$ de medio por tubo, con las sales básicas del medio MS en su concentración original, adicionado con 30 gr. $\mathrm{L}^{-1}$ de sacarosa, phytagel 3.5 gr.L-1 ${ }^{-1}$ Ácido Naftalenacético (ANA) (0.01 mg.. $\left.\mathrm{L}^{-1}\right)$, Bencil-aminopurina (BAP) (0.1 mg. $\left.\mathrm{L}^{-1}\right)$ y Thidiazuron (TDZ) (0.01, $\left.0.1 \mathrm{mg} . \mathrm{L}^{-1}\right)$, y ajustado a $5.8 \mathrm{de} \mathrm{pH}$ con $\mathrm{KOH}$ o $\mathrm{HCl}$ antes de agregar el agente gelificante; luego se realizó la esterilización por calor húmedo en una autoclave a una presión de 1.46 k. $\mathrm{cm}^{-2}$ durante 20 minutos. Es preciso señalar que los cultivos fueron incubados bajo las mismas condiciones antes mencionadas. Por último, para cuantificar el proceso morfogénico al cabo de 60 días se evaluó el porcentaje de explante con yemas y el número de yemas por explante. 


\section{Diseño experimental y análisis estadístico}

Las variables fueron evaluadas con arreglo factorial en un diseño completamente aleatorizado de 8 tratamientos, con tres repeticiones de 10 unidades experimentales compuestas por un explante (Tabla 1). Los datos fueron sometidos a un análisis de normalidad mediante el test de Shapiro-Wilk modificado y de homocedasticidad mediante la prueba de Levene; posteriormente, se realizó un análisis de variancia sobre los datos de las variables y las medias fueron comparadas entre sí por la prueba de comparaciones múltiples de Tukey, con un nivel de confianza de 0.05, para determinar el grado de significancia entre los distintos tratamientos por medio del software InfoStat (Di Rienzo et al., 2016).

\section{RESULTADOS}

La desinfección realizada en este estudio permitió conseguir un cultivo libre de contaminación visible en un $97.73 \%$ y una germinación del $86.36 \%$, con lo cual se obtuvieron plántulas asépticas, vigorosas y con radícula y vástago de normal desarrollo.

Por otro lado, la utilización del medio MS suplementado con BAP, ANA y TDZ favoreció la inducción de organogénesis en segmentos de hojas y entrenudos. De los explantes utilizados el que tuvo mayor capacidad morfogénica fue el segmento de entrenudos, manifestando diferencias significativas $(F=3.70$, $p$-valor $=0.014)$ en la variable porcentaje de explantes con yemas (Figura 1). El mejor tratamiento para la inducción de yemas adventicias fue la combinación $0.1 \mathrm{mg} \cdot \mathrm{L}^{-1} \mathrm{BAP}$ con $0.01 \mathrm{mg} . \mathrm{L}^{-1} \mathrm{TDZ}$, donde se logró un porcentaje de regeneración del $26.67 \pm 5.77 \%$ para los segmentos de entrenudos. En cuanto a los segmentos de hojas la respuesta morfogénica fue inferior, sin embargo, el tratamiento que manifestó mayor porcentaje de explantes con yemas ocurrió al adicionar al medio $0.01 \mathrm{mg} . \mathrm{L}^{-1}$ de ANA y TDZ en sus dos concentraciones $\left(0.01-0.1 \mathrm{mg} . \mathrm{L}^{-1}\right)$, aunque sin diferencias significativas con los demás tratamientos (Figura 1).

Transcurridos 60 días del cultivo, en los explantes de hojas solo se observaron yemas, en tanto que en los entrenudos se observaron yemas y brotes de hasta $13 \mathrm{~mm}$ de longitud. El número promedio de yemas por explante fue de $3.33 \pm 0.58$ a $12.00 \pm 4.36$ en los distintos tratamientos, observándose la mayor cantidad de yemas adventicias -para ambos explantes- en aquellos tratamientos en los que se adicionó $0.01 \mathrm{mg} . \mathrm{L}^{-1}$ de TDZ y $0.1 \mathrm{mg} . \mathrm{L}^{-1}$ de BAP al medio basal, si bien no se observaron diferencias estadísticas entre los tratamientos (Figura 2).

Tabla 1. Tratamientos según las dosis de Ácido Naftalenacético (ANA), Bencil-aminopurina (BAP) y Thidiazuron (TDZ), y el tipo de explante

\begin{tabular}{|c|c|c|c|c|c|}
\hline Tratamientos & $\begin{array}{c}\text { Repetición } \\
\text { 3.(n) }\end{array}$ & $\begin{array}{c}\text { ANA } \\
\text { mg.L }\end{array}$ & $\begin{array}{c}\text { BAP } \\
\text { mg. } .^{-1}\end{array}$ & $\begin{array}{c}\text { TDZ } \\
\text { mg.L }\end{array}$ & Explante \\
\hline 1 & 10 & 0.01 & --- & 0.01 & Hoja \\
\hline 2 & 10 & 0.01 & --- & 0.1 & Hoja \\
\hline 3 & 10 & --- & 0.1 & 0.01 & Hoja \\
\hline 4 & 10 & --- & 0.1 & 0.1 & Hoja \\
\hline 5 & 10 & 0.01 & --- & 0.01 & Entrenudo \\
\hline 6 & 10 & 0.01 & --- & 0.1 & Entrenudo \\
\hline 7 & 10 & --- & 0.1 & 0.01 & Entrenudo \\
\hline 8 & 10 & --- & 0.1 & 0.1 & Entrenudo \\
\hline
\end{tabular}




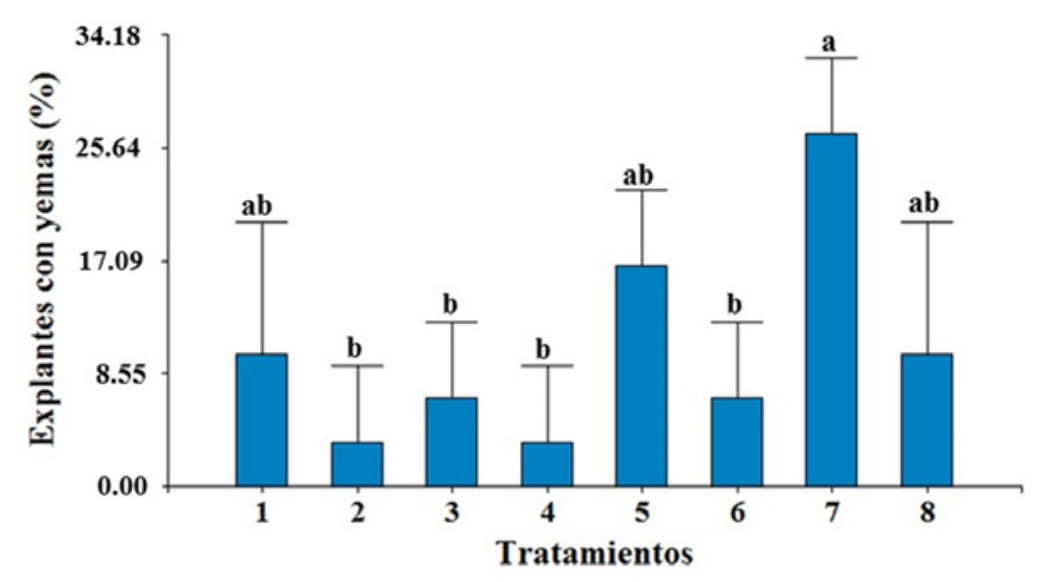

Figura 1. Efecto de las dosis y la combinación de fitohormonas sobre el porcentaje de explante con yemas en los segmentos de hojas y entrenudos.

Letras distintas indican diferencias significativas entre tratamientos a un nivel de confianza de 0.05, según el test de comparaciones múltiples de Tukey.

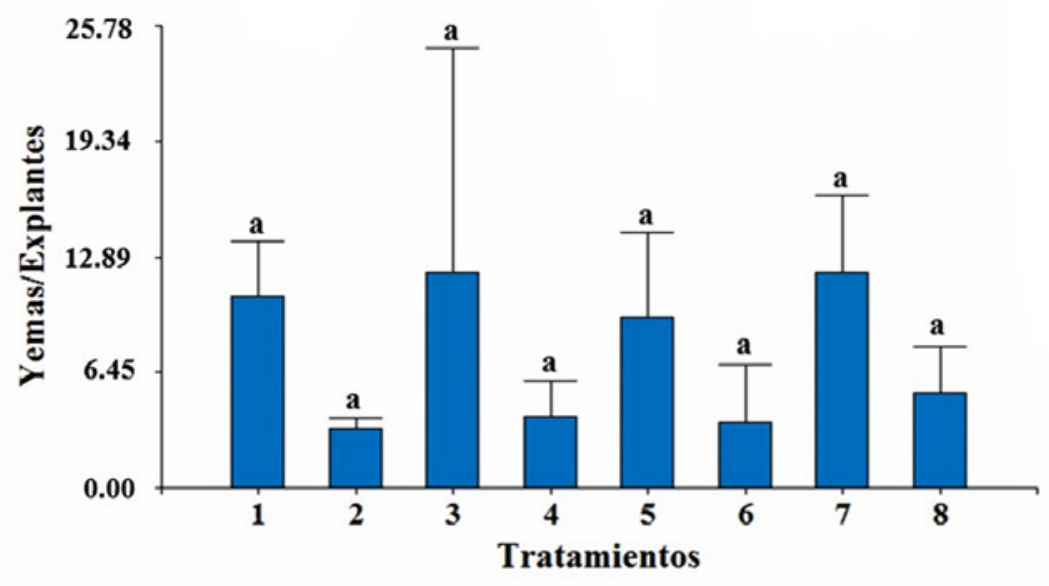

Figura 2. Efecto de los tratamientos sobre el número promedio de yemas por explantes en los segmentos de hojas y entrenudos sin diferencias significativas entre tratamientos, a un nivel de confianza de 0.05.

\section{DISCUSIÓN}

La obtención de plantas de B. riedelianum vía mecanismos convencionales por semillas tiene una eficiencia del $11 \%$ al $83 \%$ y se requieren tratamientos pregerminativos apropiados para obtener altos valores de germinación, aunque siempre se obtiene una única planta por semilla (Guollo et al., 2016; Rodrigues-Gomes et al., 2016). En cambio, en el cultivo in vitro, a través de la organogénesis adventicia, se pueden obtener una gran cantidad de plantas a partir de una pequeña porción de vegetal (García-Campusano et al., 2019). Aun así, para obtener organogénesis es necesario que 
ocurran cambios en la fisiología celular y en los mecanismos de transcripción, y también deben estar presentes fitohormonas específicas y células meristemáticas. En este sentido es que las auxinas y citoquininas desempeñan un rol importante en la formación de órganos (Sluis y Hake, 2015).

Para el caso de este estudio, se demostró que la utilización del TDZ combinado con ANA o BAP en el medio de cultivo promovieron el desarrollo de yemas en explantes de hojas y entrenudos de $B$. riedelianum. En efecto, el tratamiento en que se adicionó BAP $0.1 \mathrm{mg} . \mathrm{L}^{-1}$ con TDZ $0.01 \mathrm{mg} . \mathrm{L}^{-1}$ evidenció la mayor proporción de explantes inducidos en los segmentos de entrenudos. En consecuencia, el TDZ combinado con el BAP fue más efectivo en la inducción de brotes que la combinación TDZ-ANA, debido a que manifestaron una mayor inducción de yemas adventicias en los explantes de segmentos de entrenudos. Esta combinación BAP-TDZ también ha sido altamente efectiva en la inducción de segmentos de hipocótilo de Murraya koenigii, pero enfocada en el desarrollo de embriones somáticos (Khatik y Joshi, 2015). Por su parte, Al-Ajlouni et al. (2015) concluyeron que el agregado de TDZ al medio de cultivo favoreció significativamente la proliferación de brotes en explantes de Ruta graveolens. Así mismo, Xi et al. (2020) determinaron que la baja concentración de TDZ es favorable en la proliferación de callos y la diferenciación de brotes adventicios.

En cuanto a los explantes de hojas cultivados en un medio con TDZ-ANA, con una dosis de $0.01 \mathrm{mg} . \mathrm{L}^{-1}$, se presentó la mayor cantidad de explantes inducidos pese a que no se manifestaron diferencias significativas con los demás tratamientos. Así pues, Azad et al. (2005) informaron que la combinación TDZ-ANA, adicionado al medio de cultivo de explantes de hojas, ha generado una mayor proliferación de callos organogénicos que la combinación BAP-ANA. Por el contrario, Ahmad et al. (2010) demostraron que la mayor cantidad de explantes de hoja de Ruta graveolens fueron inducidos cuando se utilizó BAP-ANA.
Si bien las aplicaciones exógenas de citoquininas provocan cambios en los niveles de citoquininas naturales (Hare y van Staden, 1994) que estimulan la producción de brotes (Glocke et al., 2006), el TDZ es un compuesto sintético que se emplea como hormona y es considerado más efectivo que las citoquininas en la inducción y diferenciación de yemas adventicias en especies leñosas y recalcitrantes. Pese a esto, se aconseja utilizarlo en bajas concentraciones, dado que puede inhibir el crecimiento de los brotes (Huetteman y Preece, 1993; Parismoreno et al., 2016). Ahora bien, el uso individual del BAP puede inducir la proliferación de callo y desarrollo de meristemo y brotes, pero es necesario tener en cuenta que la acción de esta hormona es beneficiada a través de subcultivos con dosis mayores o combinándola con otros reguladores de crecimiento tales como el TDZ (Glocke et al., 2006) de la manera en que se realizó en este estudio.

Cabe señalar que el tipo de explante usado en la regeneración in vitro de $B$. riedelianum afecta la eficiencia de regeneración indirecta, siendo -en este caso- los explantes con mayor frecuencia de inducción de yemas adventicias los del segmento de entrenudos, tal como lo observaron Khatik y Joshi (2017), quienes utilizando de manera combinada dos citoquininas (BAP-Kinetina) obtuvieron yemas adventicias en un $82 \%$ de los entrenudos y $72.80 \%$ en hojas de Murraya koenigii. También los segmentos de hojas de este estudio presentaron la menor proporción de explantes con yemas (Figura 1), pero similar número de yemas por explante que los segmentos de entrenudos (Figura 2). Así mismo, en los explantes de hojas las yemas no elongaron en los distintos tratamientos, lo cual pudo deberse a la ontogenia del material o a la dosis de TDZ utilizada (De Melo-Ferreira et al., 2006; Monteuuis, 2004).

Por consiguiente, los resultados de este estudio han demostrado que la regeneración in vitro de yemas adventicias en segmentos de hojas y entrenudos de plántulas de un mes de edad de $B$. 
riedelianum es factible. No obstante, se requieren mayores estudios para mejorar, por un lado, la eficiencia en cuanto a la multiplicación de yemas en los explantes, y, por el otro, las siguientes fases del protocolo in vitro hasta obtener plantas completas, ya que la supervivencia en campo de un vegetal depende de la calidad de la planta y esta, a su vez, tiene estrecha relación con los aspectos morfológicos y ecológicos que adquieren las plantas durante el proceso de propagación (Chávez y de Feria, 2012; Rueda-Sánchez et al., 2014). En este sentido, la biotecnología puede contribuir a desarrollar protocolos de propagación o de mejoramiento genético, para lo cual es necesario contar con sistemas de regeneración de plantas que empleen las técnicas de organogénesis y embriogénesis (Gálvez-Tuesta y Chico-Ruíz, 2016). Por lo que los resultados de este estudio serían de utilidad para contribuir a la conservación de esta especie, al proponer protocolos de dispersión -sobre la base de segmentos de hojas y entrenudosque permitan masificar su propagación a partir de unas pocas semillas.

\section{CONCLUSIONES}

En $B$. riedelianum la proporción de explantes con organogénesis adventicia es influenciada por el tipo de explante, hormonas y dosis utilizadas, siendo más efectivo el segmento de entrenudos y la combinación de BAP-TDZ a baja concentración. En cambio, la cantidad de yemas obtenidas por explantes no es afectada por los factores estudiados aquí.

Estos resultados aportan información relevante que puede contribuir a generar protocolos de propagación para programas de conservación, enriquecimiento o reforestación con $B$. riedelianum en la región del Bosque Atlántico, entre Brasil y Argentina. Además, pueden ser utilizados como base para crear bancos de germoplasmas in vitro que también aporten para conservar la especie a largo plazo.

\section{AGRADECIMIENTOS}

La autora agradece a la Facultad de Ciencias Forestales de la Universidad Nacional de Misiones (UNaM) por el apoyo, los insumos y los equipamientos necesarios para la realización de este trabajo.

\section{CONTRIBUCIÓN POR AUTOR}

La autora es la única responsable de la obra en todos los aspectos que condujeron a la elaboración de su publicación.

\section{CONFLICTO DE INTERESES}

La autora declara que no existen conflictos de intereses.

\section{REFERENCIAS}

Aguiar, B. I., Freitas, M. L. M., Zannato, A. S., Tambarussi, E. V., Moraes, M. L. T., Ambrosano, M. N., Pereira L. C. S. M., Gandara F. B., Kageyama P. Y. y Sebbenn, A. M. (2020). The effects of pollen dispersal and mating pattern on inbreeding depression and hybrid vigor in Balfourodendron riedelianum (Engl.) Engl. (Rutaceae). Conservation Genetics, 21(2), 305-317.

https://doi.org/10.1007/s10592-020-01250-0

Ahmad, N., Faisal, M., Anis, M. y Aref, I. M. (2010). In vitro callus induction and plant regeneration from leaf explants of Ruta graveolens L. South African Journal of Botany, 76(3), 597-600. https://doi.org/10.1016/j.sajb.2010.03.008

Al-Ajlouni, Z. I., Abbas, S., Shatnawi, M. y Al-Makhadmeh, I. (2015). In vitro propagation, callus induction, and evaluation of active compounds on Ruta graveolens. Journal of Food Agriculture and Environment, 13(2), 101-106.

https://doi.org/10.1234/4.2015.3943 
Álvarez, J. C., Beltrán, P., Diana, M. y Neftali, M. L. (2011). Evaluación de reguladores de crecimiento vegetal en la organogénesis de Gmelina arborea roxb. Revista Tumbaga, 6, 107-124.

Assad, A. A. V., Ballarin, A. W., Freitas, M. L. M. y Longui, E. L. (2020). Effect of provenances on wood properties of Balfourodendron riedelianum. Madera y bosques, 26(1), 1-11. https://doi.org/10.21829/myb.2020.2611905

Azad, M. A. K., Yokota, S., Ohkubo, T., Andoh, Y., Yahara, S. y Yoshizawa, N. (2005). In vitro regeneration of the medicinal woody plant Phellodendron amurense Rupr. through excised leaves. Plant Cell, Tissue and Organ Culture, 80(1), 43-50. https://doi.org/10.1007/s11240-004-8809-5

Benítez, B., González, F., Pérez, S. y Bertoni, S. (2018). Elaboración de artesanía popular en madera en comunidades urbanas de Asunción, Areguá y Tobatí (Paraguay). Botanica complutensis, 42, 149-160. https://doi.org/10.5209/BOCM.61374

Bonga, J. M., Klimaszewska, K. K. y von Aderkas, P. (2010). Recalcitrance in clonal propagation, in particular of conifers. Plant Cell, Tissue and Organ Culture (PCTOC), 100(3), 241-254.

https://doi.org/10.1007/s11240-009-9647-2

Chávez, M. y de Feria, M. (2012). Aspectos básicos de la propagación in vitro del género Pinus por organogénesis. Biotecnología Vegetal, 12(3), 131-142.

Córdova, A. M., Cobos, M., Imán, S. A. y Castro, J. C. (2014). Un método eficiente para la inducción de callos in vitro en Myrciaria dubia (Kunth) Mc Vaugh "Camu Camu". Scientia Agropecuaria, 5(1), 25-34. https://doi.org/10.17268/sci.agropecu.2014.01.03

De Melo Ferreira, W., Kerbauy, G. B., Kraus, J. E., Pescador, R. y Suzuki, R. M. (2006). Thidiazuron influences the endogenous levels of cytokinins and IAA during the flowering of isolated shoots of Dendrobium. Journal of Plant Physiology, 163(11), 1126-1134.

https://doi.org/10.1016/j.jplph.2005.07.012

Di Rienzo, J., Balzarini, M., González, L., Casanoves, F., Tablada, M. y Robledo, C. W. (2016). InfoStat (Versión 2017) [Software de computador]. Universidad
Nacional de Córdova (UNC). https://www.infostat. com.ar/

Domínguez-Perales, L. A., Domínguez-Álvarez, J. L., Cruz-Izquierdo, S., Santacruz-Varela, A., Barrientos-Priego, A., Padilla-Ramírez, J. S. y Gutiérrez-Espinosa, M. A. (2016). Propagación in vitro de selecciones de guayabo (Psidium guajava L.). Revista fitotecnia mexicana, 39(3), 285-295.

FVSA [Fundación Vida Silvestre Argentina] y WWF [World Wildlife Fund]. (2017). El estado del Bosque Atlántico: tres países, 148 millones de personas, uno de los bosques más ricos del Planeta.

https://www.vidasilvestre.org.ar/?18821/Nueva -publicacin-El-Estado-del-Bosque-AtIntico

Gálvez-Tuesta, O. y Chico-Ruiz, J. (2016). Callos embriogénicos inducidos en tallos de Persea americana Mill. "palto" con diferentes combinaciones de reguladores del crecimiento. Sagasteguiana, 4(1), 39-50.

https://revistas.unitru.edu.pe/index.php/REVSAGAS /article/view/2510

García-Campusano, F. T. A., Mojarás-González, G., Galindo-Flores, G., Ponce-Mendoza, A., Chávez-Ávila, V. M. y Márquez-Guzmán, J. (2019). Morfogénesis in vitro de brotes adventicios del pinabete mexicano Pseudotsuga menziesii (Mirb.) Franco. Revista mexicana de ciencias forestales, 10(56), 113-135. https://doi.org/10.29298/rmcf.v10i56.545

Glocke, P., Collins, G. y Sedgley, M. (2006). 6-Benzylamino purine stimulates in vitro shoot organogenesis in Eucalyptus erythronema, E. stricklandii and their interspecific hybrids. Scientia Horticulturae, 109(4), 339-344.

https://doi.org/10.1016/j.scienta.2006.05.010

Guollo, K., Felippi, M., Possenti, J. C., Debastiani, A. B., Otalakoski, J. y Corrêa, B. J. S. (2016). Avaliação do potencial germinativo de sementes de Balfourodendron riedelianum. Nucleus, 13(2), 153-157.

https://doi.org/10.3738/1982.2278.1669

Hare, P. D. y van Staden, J. (1994). Cytokinin oxidase: biochemical features and physiological significance. Physiologia Plantarum, 91(1), 128-136.

https://doi.org/10.1111/j.1399-3054.1994.tb00668.x 
Huetteman, C. A. y Preece, J. E. (1993). Thidiazuron: a potent cytokinin for woody plant tissue culture. Plant Cell, Tissue and Organ Culture, 33(2), 105-119.

https://doi.org/10.1007/BF01983223

Khatik, N. y Joshi, R. (2015). Protocol for regeneration of plantlets through somatic embryogenesis from hypocotyl of curry leaf plant (Murraya koenigii L. Spreng). Journal of Phytological Research, 28(1- 2), 25-32.

Khatik, N. y Joshi, R. (2017). An efficient protocol for in vitro shoot regeneration from different explants of Murraya koenigii (L.) Spreng. Journal of Phytological Research, 30(1), 59-67.

Kumari, R. U., Lakshmi, S. M. y Thamodharan, G. (2015). Effect of growth hormones for direct organogenesis in Bael (Aegle marmelos (L.) corr). Journal of Applied and Natural Science, 7(1), 98-101. https://doi.org/10.31018/jans.v7i1.570

Lanzone, C., Labaroni, C. A., Formoso, A., Buschiazzo, L. M., da Rosa, F. y Teta, P. (2018). Diversidad, sistemática y conservación de roedores en el extremo sudoccidental del Bosque Atlántico Interior. Revista del Museo Argentino de Ciencias Naturales, 20(1), 151-164.

Lisboa, T. de F. B., Cielo-Filho, R., Câmara, C. D. y da Silva, W. B. (2016). Aspectos botânicos e ecossistêmicos como subsídio à interpretação ambiental na trilha do Parque Municipal Farroupilha, Oeste do Paraná. Revista Brasileira de Educação Ambiental (RevBEA), 11(2), 74-90.

https://doi.org/10.34024/revbea.2016.v11.2223

Monteuuis, O. (2004). In vitro micropropagation and rooting of Acacia mangium microshoots from juvenile and mature origins. In Vitro Cellular \& Developmental Biology-Plant, 40(1), 102-107.

https://doi.org/10.1079/IVP2003493

Murashige, T. y Skoog, F. (1962). A revised medium for rapid growth and bio assays with tobacco tissue cultures. Physiologia Plantarum, 15, 473-497.

https://doi.org/10.1111/j.1399-3054.1962.tb08052.x

Niella, S. P., Noguera, A. M., Vera, J. L. y Niella, F. O. (1996). Cultivo in vitro de guatambú blanco
(Balfourodendron riedelianum) y cedro misionero (Cedrela fissilis). Revista Forestal Yvyraretá, 7(6), 43-46.

Olmos, S., Luciani, G. y Galdeano, E. (2010). Micropropagación. En G. Levitus, V. Echenique, C. Rubinstein, E. Hopp y L. Mroginski (Eds.), Biotecnología y mejoramiento vegetal II (pp. 354-362). Instituto Nacional de Tecnología Agropecuaria, Argentina. https://exa.unne.edu.ar/biologia/fisiologia.vegetal/ BiotecnologiayMejoramientovegetalll.pdf

Parismoreno, L., Gordillo, F. y Santos, E. (2016). Determinación de tidiazurón (tdz) para la fase de multiplicación in vitro de caimito (Chrysophylum cainito L.). Yachana Revista Científica, 5(2), 25-31.

Rodríguez-Beraud, M. M., Latsague-Vidal, M. I., Chacón-Fuentes, M. A. y Astorga-Brevis, P. K. (2014). Inducción in vitro de callogénesis y organogénesis indirecta a partir de explantes de cotiledón, hipocótilo y hoja en Ugni molinae. Bosque (Valdivia), 35(1), 111-118.

https://doi.org/10.4067/S0717-92002014000100011

Rodrigues-Gomes, D., Machado-Araujo, M., Rossi-Nunes, U. y Carpenedo-Aimi, S. (2016). Biometry and germination of Balfourodendron riedelianum Eng. Eng. Journal of Seed Science, 38(3), 187-194.

http://dx.doi.org/10.1590/2317-1545v38n3159311

Rueda-Sánchez, A., Benavides-Solorio, J. de D., Saenz-Reyez, J., Muñoz Flores, H. J., Prieto-Ruiz, J. Á. y Orozco-Gutiérrez, G. (2014). Calidad de planta producida en los viveros forestales de Nayarit. Revista mexicana de ciencias forestales, 5(22), 58-73.

Schneider, C. F., Dranski, J. A. L., Gusatto, F. C., de Matos Malavasi, M. y Malavasi, U. C. (2017). Equações de longevidade para sementes de pau-marfim. Revista de Ciências Agrárias Amazonian Journal of Agricultural and Environmental Sciences, 60(1), 53-59.

http://dx.doi.org/10.4322/rca.2259

Sluis, A. y Hake, S. (2015). Organogenesis in plants: initiation and elaboration of leaves. Trends in Genetics, 31(6), 300-306.

https://doi.org/10.1016/j.tig.2015.04.004 
Vidal Cob-Uicab, J., Sabja, A. M., Ríos-Leal, D., Lara-Aguilar, A., Donoso, P. J., González, M. E. y Escobar, B. (2011). Potencial de la organogénesis como estrategia para la masificación in vitro de Fitzroya cupressoides en Sudamérica Austral. Revista Chapingo Serie Ciencias Forestales y del Ambiente, 17(3), 423-433.

https://doi.org/10.5154/r.rchscfa.2010.11.118

Villalobos, V. M. y Thorpe, T. A. (1991). Micropropagación: conceptos, metodología y resultados. En W. M. Roca y L. A. Mroginski (Eds.), Cultivo de tejidos en la agricultura: fundamentos y aplicaciones (pp. 127-141). Centro Internacional de Agricultura Tropical (CIAT). http://ciat-library.ciat.cgiar.org/Articulos_Ciat/biblioteca/Cultivo_de_tejidos_en_la_ agricultura.pdf
Villanueva, F., Ávila, M., Mansilla, A., Abades, S. y Cáceres, J. (2013). Efecto de auxinas y citoquininas en el cultivo de tejido de Ahnfeltia plicata (Hudson) Fries, 1836 (Ahnfeltiales, Rhodophyta) de la región de Magallanes. Anales del Instituto de la Patagonia, 41(1), 99-111. Universidad de Magallanes. http://dx.doi.org/10.4067/S0718-686X2013000100009

Wang, H. M., Chen, Y. J., Yu, H. D. y Zu, Y. G. (2011). Adventitious shoot regeneration from in vitro stem explants of Phellodendron amurense. African Journal of Biotechnology, 10(64), 14024-14028.

https://doi.org/10.5897/AJB11.1569

Xi, Y. K., Wang, Y., Zeng, B., Huang, H. Y. y Yang, W. D. (2020). Callus induction and adventitious bud differentiation of Cyclocodon lancifolius (Roxb.) Kurz. Botanical Sciences, 98(4), 534-544.

https://doi.org/10.17129/botsci.2609

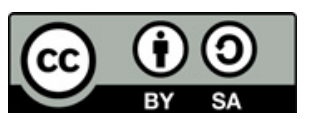

